\title{
Sarcopenia: Current Clinical and Research Issues
}

\author{
Matteo Cesari ${ }^{*}, 1$, Alessandro Ferrini ${ }^{2}$, Valentina Zamboni ${ }^{2}$ and Marco Pahor ${ }^{1}$ \\ ${ }^{I}$ Department of Aging and Geriatric Research, University of Florida, Institute on Aging, Gainesville, FL, USA \\ ${ }^{2}$ Department of Gerontological, Geriatric and Physiatric Sciences, Catholic University of Sacred Heart, Rome, Italy
}

\begin{abstract}
Sarcopenia is the age-related progressive decline of muscle mass, strength and function. It is not due to diseases, but a normal part of the aging process, and multiple physiological and psychological factors seem to contribute to it. Sarcopenia has been associated with a higher risk of falls, incident disability and all-cause mortality in the elderly. Despite this phenomenon has major clinical, social and economic consequences in older persons, its study is still limited and/or partial. The major issues making difficult the design of clinical trials on sarcopenia are: the multidimensional physiological mechanisms determining it, the lack of standardized definitions, the difficulties in operatively defining this dynamic mechanism, and the different methodologies able to estimate the muscle mass and function. The present review will 1) overview the current clinical and research issues related to the study of sarcopenia in the elderly, and 2) discuss the possible solutions on the basis of evidence on the topic.
\end{abstract}

\section{DEFINITION OF SARCOPENIA}

The term "sarcopenia" (from Greek sarx for flesh, and penia for loss) is commonly used to describe one of the most noticeable age-related modifications, that is the progressive decline of muscle mass, strength and function [1, 2]. Skeletal muscle declines in both men and women with aging. Muscle strength and mass reach their peaks in the teens and twenties, and begin to fall in the thirties. A $10-15 \%$ rate of decline in muscle strength has been estimated per decade of life after the age of 50 years. This decline becomes even faster after 75 years of age [3].

The sarcopenia phenomenon has been reported in a wide range of species in animals as well as in humans. After all, if this loss of muscle mass is an age-related phenomenon, it ought to be universal because every living being is aging. For example, progressive loss of muscle mass and function has been reported in Caernorhabditis elegans, a short-lived nematode, extensively studied to explore the aging process, and whose genome was completely sequenced [4]. In fact, a gradual disorganization and decrease in myosin thick filaments in the sarcomeres of older Caernorhabditis elegans have been observed. Similarly to what occurring in humans, nematodes with earlier motor dysfunction show lower life expectancies.

Sarcopenia is a bidimensional phenomenon (Fig. 1) [5], because simulatenously considering (by definition) declines in both quantity (i.e., muscle mass) and quality (i.e. muscle function/strength). Nevertheless, large part of the current evidence on the topic is mainly focused on muscle function/strength modifications rather than also considering the parallel body composition changes. Although this choice (primarily due to the availabity of better assessment methods) might be legitimate because considering the skeletal

*Address correspondence to this author at the Department of Aging and Geriatric Research, University of Florida - Institute on Aging, P.O. Box 112610, Gainesville, FL 32611, USA; Tel: +1 (352) 273-5917; Fax: +1 (352) 273-5920; E-mail: macesari@gmail.com muscle decline through a component of it (i.e. strength and function loss), it is still limiting the evaluation to a monodimensional approach.

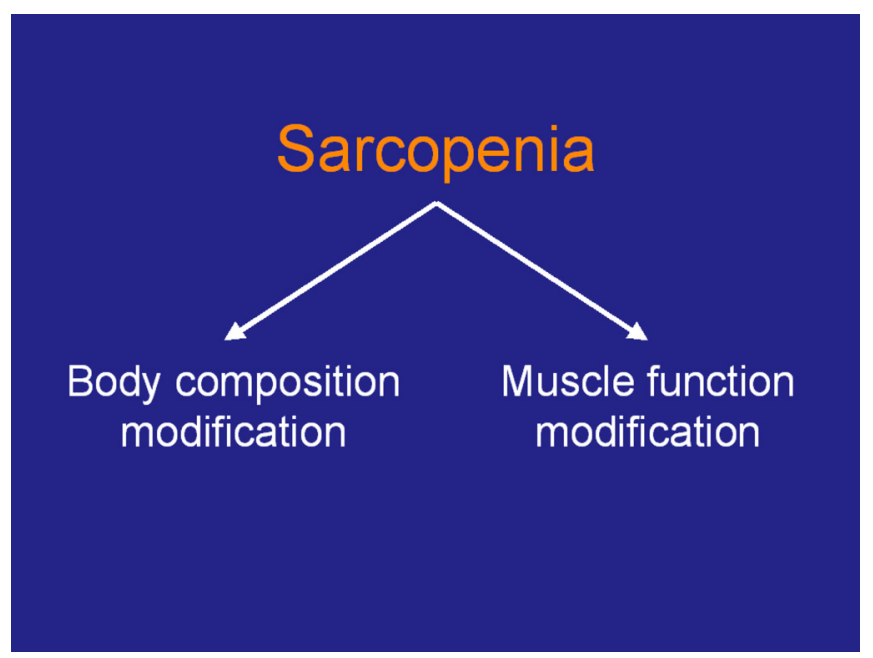

Fig. (1). The bi-dimensional nature of sarcopenia.

Sarcopenia might be considered as the "muscular component" of the frailty syndrome, sharing with it the multicausal nature and the dynamic process [6]. In fact, sarcopenia is not only characterized by common features with this geriatric syndrome, such as poor endurance, physical inactivity, slow gait speed, muscle fatigability, and decreased mobility $[7,8]$. It is also associated with an increased risk of several major health-related events in older persons, including physical disability and mortality $[9,10]$. Besides the major clinical consequences, sarcopenia is also extremely burdensome on the health care system from an economic point of view. In fact, it has been estimated that the health care costs due to sarcopenia in the United States in 2000 were about $\$ 18.5$ billion [11]. It is likely this figure will significantly increase in the next future due to the progressive aging of the population. 
Unfortunately, several conceptual and methodological issues limit the study of this phenomenon, so that sarcopenia is often considered as a mere "matter for researchers" with low clinical relevance. Moreover, the lack of standardized (operative) definitions, standardized methodologies to measure the muscle decline, and the inability to properly capture the dynamicity of the sarcopenia process are responsible for controversies and inconsistencies in literature. These difficulties are likely to explain the extreme scarcity of clinical trials considering sarcopenia as primary outcome.

In the present review, we discuss the current issues limiting the study of sarcopenia, and provide some recommendations for methods, techniques, and measurements to consider in the evaluation of the age-related muscle decline. Moreover, we suggest which biological and clinical features should be considered in the recruitment of potential participants to clinical trials on sarcopenia. Finally, we discuss the role that physical exercise/activity as preventive/treatment strategy against the age-related skeletal muscle loss.

\section{CONCEPTUAL ISSUES ABOUT SARCOPENIA IN THE NEED OF CLARIFICATION}

As stated above, sarcopenia represents one most the most evident effects of the aging process on our organism. Therefore, its study may be able to clarify many mechanisms related to aging, and potentially open new scenarios for preventive medicine. Nevertheless, its definition implies several conceptual issues that are not easy to overcome when translating the hypotheses into the research field.

One of the major problems found by researchers when designing clinical trials on sarcopenia resides in the longterm nature of this process over time. In fact, the age-related decline of skeletal muscle starts in the thirties to develop throughout the life. Moreover, by definition, it is a continuous process strongly connected with age, so that everyone experiences this skeletal muscle decline. Considering these two facts together, a clinical trial on sarcopenia should consider an extremely long follow-up (with consequent high costs) to evaluate whether, for example, a specific intervention is capable to reduce the already slow body composition changes occurring with age (and even experienced by any possible control group) [5]. Translational studies on animal models may partly solve these issues by providing preliminary data to be later verified in humans. However, the evaluation of the long sarcopenia process still remains difficult to exhaustively evaluate in humans. Several studies have solved this issue by comparing results obtained from a sample of healthy older individuals to a sample of healthy young controls. This approach implicitly accepts that the simple absence of clinical conditions makes similar and comparable a young person in his/her twenties to an older subject in his/her sixties (or even more). The exclusion of clinical conditions may appear able to isolate the "normal" aging process from all the potential confounders influencing it. Unfortunately, although this approach may be legitimate (and possibly the best way to study the long-term phenomenon of aging), it has several limitations, such as not considering the role played by cultural, lifestyle and subclinical factors/conditions.
When approaching the sarcopenia topic, it is evident the large controversy existing behind the clinical meaning of this condition. If sarcopenia is not a disease, why do we want to "treat" it? Some reasons might be found in several papers presenting the loss of muscle mass as an age-related phenomenon potentially leading to severe health consequences $[9,10]$. However, a growing part of evidence is refusing the hypothesis that sarcopenia is a risk factor for health-related events. In fact, several Authors have increasingly observed that fat tissue (and intramuscular fat infiltration) is the real responsible for the onset of health-related events rather the lean tissue [12-14]. Consequently, preventing or delaying sarcopenia may not be particularly important because of the uncertain role that skeletal muscle per se may have on health. Further studies are needed to clarify this issue because of crucial importance for the definition of the clinical importance of sarcopenia. In fact, if sarcopenia is just considered as the manifestation of the aging process on the skeletal muscle, the study of this phenomenon may imply the shifting from a geriatric to a gerontological field.

It is noteworthy that most Authors tend to give a larger importance to the functional component of sarcopenia (i.e. loss of muscle strength) rather than to its apparent one (i.e. loss of muscle mass). If this may represent a way to explore a still largely uncovered field, it is important to take into account how the functional surrogates of sarcopenia (e.g. physical function measures) may go beyond mere measures of muscle strength, but represent markers of well-being.

Therefore, an intervention improving muscle strength (and, consequently, increasing muscle mass) may not necessarily be beneficial because intervening on the skeletal muscle. Its benefits may find a broader explanation in an overall improvement and in the inhibition of the physical decline vicious cycle.

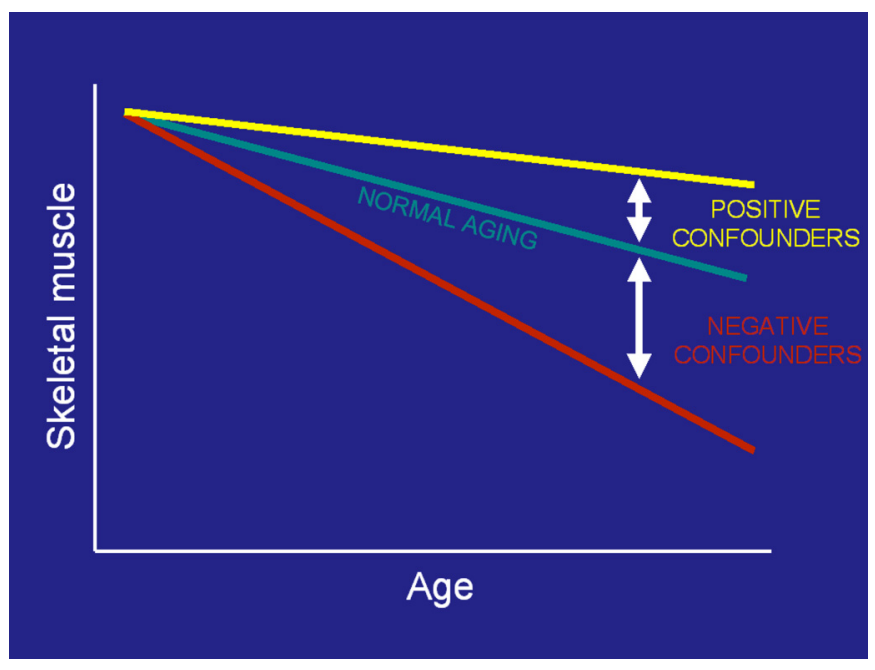

Fig. (2). Muscle decline is influenced by positive and negative factors modifying the "normal aging" trajectory.

Another major limitation influencing the design and development of clinical trials on sarcopenia is the wide spectrum of potential confounders able to (negatively or positively) affect the skeletal muscle decline (Fig. 2) [15-17]. In fact, multiple sociodemographic (e.g. gender, race/ethnicity), behavioral (e.g., physical inactivity, malnutrition, smoking...), biological (e.g. inflammation...), and clinical (e.g. 
clinical conditions...) factors are able to accelerate the normal age-related muscle decline trajectory. On the other hand, positive confounders also exist capable to reduce the skeletal muscle decline rate (e.g. physical activity, hormone replacement therapy, immunomodulatory medications...). If sarcopenia is a pure age-related phenomenon, the study of it should carefully exclude all these positive and negative confounders able to modify the aging process of the muscle. Only in this way we will be able to capture the real and only aging effect. Otherwise, these confounders may potentially be responsible for biased results. The translation of this concept is extremely hard into practice, especially because sarcopenia is a phenomenon of older age, when subjects tend to present a higher number of (sub)clinical conditions.

\section{CURRENT METHODOLOGIES TO MEASURE SKELETAL MUSCLE MASS}

One of the major restrains to the design and development of clinical trials on sarcopenia resides in the multiple imaging methodologies that can be adopted to estimate the skeletal muscle parameters. If sarcopenia has to be considered as a condition worth to be investigated in clinical trials, a unique and standardized method of assessment of the skeletal muscle is needed. Moreover, the standardization of the skeletal muscle assessment may facilitate the identification of a possible critical threshold distinguishing the age-related phenomenon from the clinically relevant risk factor for negative events.

Currently, the most used techniques to evaluate the skeletal muscle mass include anthropometry, creatinine excretion, bioelectrical impedance analysis (BIA), peripheral quantitative computerized tomography (pQCT), dual energy X-ray absoptiometry (DEXA), neutron activation, computerized tomography (CT), and magnetic resonance imaging (MRI). A list of the major strengths and weaknesses of all these techniques is presented in Table 1. MRI and CT represent by far the most accurate imaging methods to determine muscle mass. They are also able to provide parameters of muscle quality (e.g. muscle density, intramuscular infiltrates of fat). Nevertheless, the high costs and the technical difficulties of these procedures make them difficult to be implemented in large and/or not sufficiently funded clinical trials. The pQCT can be considered as a legitimate alternative to these "gold standards", even if a loss of accuracy is implied. This methodology is based on a portable CT scanner able to measure cross-sectional areas of bone (including its subcompartments), muscle, and adipose tissue at upper and lower limbs. Moreover, muscle and bone density can be measured as well. A limitation common to all these three methodologies is related to the lack of adjustment for body size (consequently requiring a second measure). In fact, for example, a higher muscle area might just reflect a larger body size rather than a healthier status of the assessed skeletal muscle. Moreover, it should not be underestimated that these techniques provide results estimating muscle mass in a specific part (slice) of the body, so that the generalization of results to the whole organism (or even to other parts of the same district) might be arguable. An alternative method to estimate the entire body muscle mass is based on the in vivo neutron activation analysis combined with the $40 \mathrm{~K}$ whole body counting [18, 19]. The rationale of this method is based on the existence of a difference in the potassium-to-nitrogen ratio between the skeletal muscle and the non-skeletal muscle tissues. If total body potassium (from the $40 \mathrm{~K}$ whole body counting) and total body nitrogen (from prompt- $\gamma$ neutron activation analysis) are known, these ratios can be mathematically derived and applied to predict the subject's skeletal muscle mass. However, besides of the still unclear validity, this method is even more expensive than CT [20].

The application of DEXA for the muscle mass estimation has created an attractive alternative to more expensive methods. However, it needs to be taken into account when considering this technique that the accuracy of DEXA for predicting muscle mass in people of different age groups and in some pathological conditions may vary. For example, there is a tendency for DEXA to overestimate muscle mass [20], possibly because this method does not differentiate between water and bone-free lean tissue. This might lead to significant bias in older persons due to extracellular fluid accumulation [21].

Theoretically, the measurement of urinary creatinine excretion is one of the most specific indexes of total body skeletal muscle mass because creatine, the precursor of creatinine, originates almost exclusively from skeletal muscle. Unfortunately, creatinine excretion shows a daily variation, consequently providing an inaccurate estimate. Moreover, to assess urinary creatinine excretion, the subject is required to be on a meat-free diet for few days and a prolonged urine collection is needed [21].

Even if inexpensive, anthropometric measurements are very limited in their accuracy [22]. Rolland and colleagues [23] showed that calf circumference is only moderately correlated with appendicular lean mass as determined by DEXA scan. Moreover, anthropometric measures are based on certain uncertain assumptions about the adipose tissue distribution (along the length and circumference of the limbs), and the mean cross-sectional area of muscles and bones [24, 25]. Moreover, malnutrition, comorbidities, and/or poor health status (as frequently occurring in older persons) may furtherly bias the estimate of muscle mass with anthropometric measures (mainly due to the reduced amount of subcutaneous adipose tissue).

\section{THE LACK OF A WELL-ESTABLISHED DEFINING CUT-POINT FOR SARCOPENIA}

A standard and widely-accepted quantitative definition of sarcopenia is not currently available in literature. All the biological measures to be clinically meaningful require to be categorized, so to identify a critical threshold distinguishing a "normal" vs an "at risk" value. Moreover, the identification of a cut-point also provides a target to theoretically establish whether a specific intervention is successful or not. Sarcopenia is not an exception. Unfortunately, several issues limit the identification of such cut-point.

First of all, it is important to keep in mind that the initial amount of muscle mass (and strength) plays a major role in the muscle decline process [6]. In fact, as Marcell noted [26], the level of initial muscle mass (as well as the muscle quality) are crucial in reaching the clinically-meaningful threshold of sarcopenia. For example, a relevant reduction of muscle mass in a bodybuilder may still spare an amount of lean 
Table 1. Methodologies to Estimate the Muscle Mass

\begin{tabular}{|c|c|c|}
\hline Method & Strengths & Weaknesses \\
\hline $\begin{array}{l}\text { Magnetic resonance } \\
\text { imaging (MRI) }\end{array}$ & $\begin{array}{l}>\text { Best resolution } \\
\text { Cross-sectional measurement of lean and fat mass areas in a spe- } \\
\text { cific part of the body } \\
>\begin{array}{l}\text { Evaluation of muscle quality parameters (i.e., intramuscular infil- } \\
\text { trates of fat) }\end{array}\end{array}$ & $\begin{aligned}> & \text { Highly expensive } \\
> & \text { Images of a body part which may not be appli- } \\
& \text { cable to different body districts } \\
> & \text { Time-consuming } \\
> & \text { High space requirements } \\
> & \text { Technically difficult to perform }\end{aligned}$ \\
\hline $\begin{array}{l}\text { Computerized tomogra- } \\
\text { phy (CT) }\end{array}$ & $\begin{array}{l}\text { Cross-sectional measurement of lean and fat mass areas in a spe- } \\
\text { cific part of the body } \\
>\text { Evaluation of muscle quality parameters (i.e., intramuscular infil- } \\
\text { trates of fat) }\end{array}$ & $\begin{array}{l}>\text { Images of a body part which may not be appli- } \\
\text { cable to different body districts } \\
>\text { Exposure to radiations } \\
>\text { Time-consuming } \\
>\text { High space requirements } \\
>\text { Technically difficult to perform }\end{array}$ \\
\hline $\begin{array}{l}\text { Peripheral quantitative } \\
\text { computerized tomo- } \\
\text { graphy (pQCT) }\end{array}$ & $\begin{array}{l}>\text { Cross-sectional measurement of lean and fat mass areas in a spe- } \\
\text { cific part of the body } \\
>\text { Evaluation of muscle quality parameters (i.e., intramuscular infil- } \\
\text { trates of fat) } \\
>\text { Portable } \\
>\text { Does not require highly trained personnel }\end{array}$ & $\begin{array}{l}>\text { Images of a body part which may not be appli- } \\
\text { cable to different body districts } \\
>\text { Limited accuracy compared to MRI or CT } \\
>\text { Originally designed to evaluate bone parame- } \\
\text { ters, it has lower application on muscle } \\
>\text { Exposure to low dose radiation }\end{array}$ \\
\hline Neutron activation & $>$ Estimate of overall skeletal muscle mass & $\begin{aligned}> & \text { Expensive } \\
> & \text { Limited validity } \\
> & \text { Exposure to radiations } \\
> & \text { Time-consuming } \\
> & \text { Technically difficult to perform } \\
> & \text { No information about muscle quality } \\
> & \text { No information about specific body districts } \\
& \text { (e.g., limbs) }\end{aligned}$ \\
\hline $\begin{array}{l}\text { Dual energy X-ray ab- } \\
\text { sorptiometry (DEXA) }\end{array}$ & $\begin{array}{l}>\text { Sensitive and accurate method } \\
\text { Estimates of lean, fat, and bone tissues in the entire body or in } \\
\text { specific parts of it } \\
>\text { Usually present in clinic/research settings } \\
>\text { Relatively cheap } \\
>\text { Does not require highly trained personnel }\end{array}$ & $\begin{array}{l}>\text { No information about muscle quality } \\
>\text { Space requirements } \\
>\text { Exposure to low dose radiation } \\
>\text { Possible biased results due to limited differen- } \\
\text { tiation between water and bone-free lean tissue }\end{array}$ \\
\hline $\begin{array}{l}\text { Bioelectrical impedance } \\
\text { analysis (BIA) }\end{array}$ & $\begin{array}{l}>\text { Relatively inexpensive } \\
>\text { Minimal maintenance } \\
>\text { Portable } \\
>\text { Results immediately available } \\
>\text { Does not require highly trained personnel }\end{array}$ & $\begin{aligned} & \text { Results based on body resistance } \\
> & \text { No measure of muscle quality } \\
> & \text { Lower accuracy compared to other methods } \\
& \text { (i.e., MRI, CT, DEXA) }\end{aligned}$ \\
\hline Creatinine excretion & $>$ Measure directly related to total body muscle mass & $\begin{array}{l}>\text { Time-consuming } \\
>\text { Diet restrictions the days before the urine } \\
\text { collection } \\
>\text { Results not immediately available } \\
>\text { Complicated procedure } \\
>\text { Daily variation of creatinine excretion }\end{array}$ \\
\hline Anthropometry & $\begin{array}{l}>\text { Easy to assess } \\
>\text { Inexpensive }\end{array}$ & $\begin{array}{l}>\text { Very limited accuracy } \\
>\text { No information about muscle quality } \\
>\text { Nutritional status and comorbidities can easily } \\
\text { bias the results }\end{array}$ \\
\hline
\end{tabular}

mass greater than the one commonly presented by a healthy normal individual. Therefore, the greater the starting reserve capacity, the longer it will be before the critical threshold of sarcopenia is crossed.
Sarcopenia is a difficult condition to be identified in the real world. This difficulty resides in 1) the progressive and "longitudinal" nature of this phenomenon, 2) the different available methodologies to assess body composition, 3) the bi-dimensional nature of the phenomenon, and 4) the lack of 
a unique and standardized operational definition. Moreover, even if sarcopenia is defined as an age-related condition, it still is under the effect of multiple factors potentially influencing its development and progression.

According to its definition, sarcopenia is a timedependent process. Therefore, it implies a longitudinal evaluation considering a starting level of muscle mass and the rate of its decline. In other words, sarcopenia should not be defined on the basis of a one-point assessment, but always controlled for a baseline or reference value. Consequently, the definition of sarcopenia should necessarily rely on skeletal muscle change. In this context, it is important to keep in mind that 1) as stated above, multiple confounders contributing with different extents to the muscle decline produce an immeasurable variability of the process, and 2) sarcopenia is a time-dependent process occurring in muscles starting after 30 years of age. As done in previous studies, these issues can be (at least partly) solved by referring the measured muscle mass parameters to "normal" values determined at youngadult ages [1, 27]. The definition of critical cut-points from standard deviations of a reference population is at the basis of commonly used diagnostic criteria, such as for anemia [28] or osteoporosis

A different approach to define the presence/absence of sarcopenia was adopted in several studies in which the critical threshold in muscle mass loss was based on the risk for future health-related events. For example, Janssen and colleagues [29] proposed a scale of muscle loss identifying specific cut-points below which the risk for subsequent physical disability significantly increases.

A further alternative approach might be based on the population distribution (e.g. specific percentiles of muscle mass loss). If this method may have some validity in research and represents a legitimate choice to identify subjects with low muscle mass in a sample population, the translation of results to clinical practice and their generalization to the overall population might raise some concerns.

\section{CURRENT METHODOLOGIES TO MEASURE SKELETAL MUSCLE FUNCTION}

Muscle strength and mass reach their peaks in the teens and twenties, and begin to fall in the thirties. A $10-15 \%$ rate of decline in muscle strength has been estimated per decade of life after age of 50 years. This decline becomes even faster after 75 years of age [3].

When muscle strength is considered in adjunction with muscle mass may constitute a marker of muscle quality, a measure of the work that a specific muscle mass may exert. For example, by simply dividing a measure of strength for the estimate of the cell lean mass, we may obtain an optimal estimate of the skeletal muscle quality. This measure will potentially include both components of the sarcopenia phenomenon: the muscle strength and the muscle mass. For the same purpose, it can also be quantified the amount of tension produced by the muscle per unit of area in different districts. These measures of muscle quality have consistently shown to decrease with aging. Even if the muscle quality is examined at the cellular level, a difference between young and old cells can be seen, for example in terms of reduced contractility of the actin myosin complex. Moreover, it has been re- ported that the force produced by single muscle cells from young men $v s$ old men adjusted for the size of those fibers show that young fibers are stronger than old fibers [30].

As mentioned above, most of the current evidence on the age-related skeletal muscle decline derives from studies considering the muscle strength/function as primary outcome. Therefore, it might be argued that such studies are not really studying sarcopenia, but muscle strength/function, only one of the two components of the age-related skeletal muscle decline. However, we realize that a clinical trial on sarcopenia in humans may require the assessment of clinically meaningful surrogates that may be more sensible to agerelated changes than body composition parameters. The need for this "adaptation" of the study design to the clinical and research practice rather than to the implicit nature of the phenomenon is often required for economic and feasibility reasons.

Physical performance and muscle strength measures can play a major role as clinical outcomes in studies on sarcopenia. In fact, these measures are not only associated with body composition (and, particularly, with skeletal muscle parameters) [31], but have also been shown to present a better predictive value for some health-related negative events (e.g. mortality) [13]. Interestingly, Visser and colleagues [32] reported that mid-thigh muscle area is associated with increased risk of mobility disability in well-functioning older men and women, but this risk was not independent of lower knee extension strength and muscle density. Even if muscle mass explains most of the variance in muscle strength [33, 34], older persons with lower muscle mass still present a higher risk of functional decline. Newman and colleagues [13] reported in the Health Aging and Body Composition (Health ABC) study that low muscle mass does not explain the strong relationship between strength and mortality, indicating that muscle strength as a marker of muscle quality may be more important than quantity in estimating the risk of events. Interestingly, in the same study, similar results were provided by muscle strength when assessed in different muscular groups (i.e. hand grip, quadriceps). This finding is of particular importance because implicitly generalizing the measure of a single muscle group to the entire body. Therefore, in the context of the planning of a clinical trail on sarcopenia, muscle strength may indeed provide that muscle quality measure needed to qualify the muscle mass estimation. Again, the analyses of only skeletal muscle mass or skeletal muscle function/strength will provide only partial evaluations of the skeletal muscle. Both components of the skeletal muscle decline should always be considered in studies focused on sarcopenia.

According to the study requirements and availabilities, several different methods for the measurement of muscle strength can be adopted, from the simplest to the most accurate and complex dynamometers. Interestingly, a paper by Lauretani and colleagues [35] demonstrated that isometric hand grip strength not only declines with age, but is also a very strong correlate of sarcopenia when cross-sectionally compared to lower extremity muscle power, knee extension torque, or calf cross-sectional muscle area. Although these findings have to be confirmed by longitudinal studies, they 
still represent a useful basis to easily identify the loss of muscle mass (i.e. sarcopenia) even in clinical settings.

Among the measures potentially providing a clinical estimate of sarcopenia in trials, the Short Physical Performance Battery also represents an important alternative to consider. Delmonico and colleagues [12] demonstrated that sarcopenia (measured using a fat-adjusted measure) is a strong predictor of decline in Short Physical Performance Battery results. Moreover, given the strong link existing between this physical performance measure and physical disability, the translation of the test into a correlate of sarcopenia is almost consequential.

\section{BIOLOGICAL TARGETS OF CLINICAL TRIALS ON SARCOPENIA}

As previously discussed, muscle mass per se (even when adjusted for body size) may not be sufficient to correctly determine sarcopenia. In fact, a measure of quantity does not necessarily constitute a measure of quality, too. This issue needs to be taken into account when evaluating studies only basing their findings on the lean mass amount.

Additional markers may be required to more precisely evaluate the presence/absence of sarcopenia, and to provide additional information on this age-related phenomenon. These additional indicators may not necessarily be measured through imaging techniques, but be part of the individual's biological assessment.

Substantial changes in body fat accumulation occur with aging, and lipid redistribution is shown to be one of the most evident age-related physiological phenomena. It has been estimated that an adult may gain approximately $0.5 \mathrm{~kg}$ of fat every year between ages 30 to 60 years. This fat gain is parallel to a loss of about $0.25 \mathrm{~kg}$ of muscle mass [36]. In a relative stability of overall body weight, this progressive accumulation of fat may mask the presence of sarcopenia in older persons. For this reason, recent operational definitions of sarcopenia tend to simultaneously consider muscle mass and adipose tissue measures. In a Health Aging and Body Composition (Health ABC) study Newman and colleagues [37] compared two different definitions of sarcopenia. The first definition of sarcopenia was based on the lowest genderspecific quintiles of the ratio between appendicular lean mass (measured by DEXA scan) and squared height. This definition is commonly used in literature [1, 38, 39]. The second definition was based on the lowest gender-specific quintiles of the residuals obtained from linear regression models between appendicular lean mass on height and fat mass. Authors concluded that fat mass should be considered when estimating the prevalence of sarcopenia to avoid possible misclassifications of sarcopenic individuals, especially in women and in obese subjects (i.e. those with more adipose tissue).

Intramuscular fat infiltrates. Adipose tissue is directly associated with intramuscular fat infiltrates, potentially impairing muscle function [8]. Fat infiltration of muscle may partially explain such discrepancy between mass and force. The assessment of muscle density using MRI, CT, or pQCT provides a reliable and valid measure of the fatty degeneration of muscle tissue [40]. A lower muscle density is indicative of a higher intramuscular fat content which may be det- rimental for the muscle functionality due to mechanical (e.g. fat infiltrates among muscle fibers) and biological (e.g. increased inflammatory status due to secretion of adipocitokines) reasons. In fact, there is well-established evidence that adipose tissue (in any location, including in the muscle) is not inert, but largely contributes to metabolic pathways potentially promoting/exacerbating sarcopenia.

Inflammatory markers. The age-related loss of muscle mass reduces the available target tissue responsive to insulin, leading to insulin resistance, metabolic syndrome, and obesity. At the same time, fat depots produce several major inflammatory markers (e.g. tumor necrosis factor $[\mathrm{TNF}]-\alpha$, interluekin [IL]-6, IL-1) which are associated with age and obesity [41]. Pro-inflammatory cytokines are commonly involved in cachexia and have been involved in the process responsible for the anorexia of aging [42]. Since increased levels of inflammation are detrimental for skeletal muscle in humans [43] as well as in animal models [44-46], a vicious cycle is established and leads to more gain in fat and more loss of muscle.

Among the inflammatory markers that are more strongly associated with muscle mass and quality (and, consequently, of primary importance as biological surrogates/correlates of sarcopenia), TNF- $\alpha$ needs special attention. In fact, levels of this cytokine (notably, also called cachectin or cachexin) tend to increase with age in several tissues, including skeletal muscle $[47,48]$. TNF- $\alpha$ is a central mediator of cellular inflammatory and apoptotic signaling pathways (see below), and plays a major role in the aging process [47, 49]. TNF- $\alpha$ stimulates a cellular kinase complex (i.e. I Kappa B Kinase $[\mathrm{IKK}]$ ), which activates nuclear factor (NF)- $\mathrm{B}$, a transcription factor regulating the production of proinflammatory cytokines (including IL-1 and IL-6) [50].

However, several mechanisms linking inflammation and the muscle function are still unclear. For example, some inflammatory markers have sometimes shown contrastant effects in different situations. In a recent study, Schaap and colleagues showed that concentrations of $\alpha 1$ antichymotrypsin (an acute phase protein) are inversely associated with the risk of strength loss [51]. During acute bout of exercise, IL-6 is released from skeletal muscle. This production has shown to be parallel to the one of antiinflammatory cytokines (e.g. IL-1 receptor antagonist and IL-10) which are able to inhibit TNF- $\alpha$ [52]. Whether IL-6 is acting as a pro-inflammatory marker or as a factor counteracting the TNF- $\alpha$ effects is currently unexplained [53].

Inflammatory cytokines are important contributors to the muscle wasting in chronic disease, and several studies have investigated the effects of anti-cytokine antibodies as potential treatments. Thalidomide (an immunomodulatory drug) is able to inhibit TNF- $\alpha$ and selectively destabilize TNF- $\alpha$ mRNA [54]. This drug has been shown to also attenuate the loss of muscle mass and improve physical function in cancer patients $[55,56]$. A trial in patients with HIV/AIDS-related lymphoma showed reductions in fever and cachexia from anti-IL-6 therapy [57]. Unfortunately, the efficacy of such interventions is still debated and evidence largely controversial [58].

Biomarkers of oxidative damage and apoptosis. Oxidative damage biomarkers may also be useful additions in the 
evaluation of skeletal muscle decline. In fact, the relationship between oxidative damage and inflammation is very close [59]. Moreover, both these pathways have been described as interacting in several theories of aging $[60,61]$.

An ideal "golden triangle" of oxidative balance, in which oxidants, antioxidants and biomolecules are placed at each apex, has been described [62]. In a normal situation, a balanced-equilibrium exists among these three elements. Excess generation of free radicals may overwhelm natural cellular antioxidant defenses leading to oxidation and further contributing to muscle damage [63]. Interestingly, some studies have recently reported the association of oxidative damage biomarkers with low muscle strength [64], mortality [65], and incident mobility limitation [66, 67]. However, the scarse evidence in this field is limited to few markers of lipid peroxidation (i.e. oxidized low-density lipoprotein) and protein oxidation (i.e. protein carbonyls).

The activation of NF- $\mathrm{kB}$ and mitogen-activated protein kinase (MAPK) pathways in skeletal muscle has been shown to enhance the gene expression of several enzymes that play an important role in maitaining oxidant-antioxidant homeostasis, such as mitochondrial superoxide dismutase (MnSOD) and inducible nitric oxide synthase (iNOS) [68]. MAPKs and NF- $\mathrm{kB}$ are two major regulators of gene transcription and metabolism in response to oxidative, energetic, and mechanical stress in skeletal muscle. Chronic activation of these signaling pathways has been implicated in the development and perpetuation of various pathologies, such as diabetes and cachexia. However, both MAPKs and NF- $\mathrm{BB}$ are also stimulated by exercise, which promotes improvements in fuel homeostasis and can prevent muscle atrophy. Although limited, there is additional evidence to suggest cross-talk between MAPK and NF-kB signals with exercise [69]. It has been demonstrated that activation of the NF- $\mathrm{KB}$ transcription pathway, activated by cachectic factors such as TNF- $\alpha$, is sufficient to induce skeletal muscle atrophy [70].

If the oxidative damage acts as contributor to sarcopenia, estimating the antioxidant defenses might be helpful, too. In this context, recent studies have indicated carotenoids and vitamin $\mathrm{E}$ as antioxidant molecules of particular interest, given their capacity to counteract free radicals, reduce oxidative damage, and modulate redox-sensitive transcription factors (e.g. NF-kB) [71, 72]. Moreover, carotenoids and vitamin $\mathrm{E}$ are independently associated with physical performance and muscle strength measures [71, 73]. Low carotenoids levels are not only correlated with high protein carbonyl concentrations, but also predictive of severe walking disability [72], confirming the interaction between oxidative damage and antioxidant defenses in the development of negative health-related events [63]. Interestingly, vitamin E supplementation has shown to induce modest improvements to physical exercise-induced oxidative damage, by reducing resting and post-exercise increments of isoprostane concentrations [74].

Inflammation and oxidative damage are strongly associated with apoptosis, a different biological pathway potentially responsible for sarcopenia. Apoptosis is an evolutionary conserved suicide program of the cell. It is an important process for the development in multicellular organisms, the elimination of superfluous tissues, and the maintenance of tissue homeostasis in adults.

TNF- $\alpha$ (again) is one of the prime signals inducing the apoptotic program in the muscle cell [47]. TNF- $\alpha$ is capable to activate the transcription factor NF- $\kappa \mathrm{B}$, which plays a protective role in the TNF-induced apoptosis, determining a sort of negative feedback [75]. The activation of the apoptotic cascade, which has been linked to the loss of myocytes, can be promoted by the binding of TNF- $\alpha$ with its membrane receptors. TNF- $\alpha$ signalling initiates a sequence of events involving caspases (i.e. cysteine-dependent, aspartatespecific proteases). The "initiator" caspases (i.e. caspase-8, caspase-9, and caspase-12) activate the "effector" caspases (i.e. caspase-3, caspase-6, and caspase-7), which carry out the proteolytic events and the DNA fragmentation (via a caspase-activated DNAase).

Caspases represent a novel group of endoproteases which are responsible for cellular apoptosis through the protein degradation. In the cell, they are expressed as inactive precursors (i.e. procaspases). Procaspases can be activated into caspases (which will serve as apoptotic effectors - e.g. capsase-3) through mitochondrial- (i.e. release of cytochrome-c from the mitochondria forming an "apoptosome" which activates procaspase-9) and receptor- (i.e. apoptosis induced by TNF- $\alpha$ binding with its death receptor and activation of procaspase-8) mediated pathways. Besides of the caspasedependent apoptosis, a caspase-independent pathway of apoptosis exists, too. Endonuclease G (Endo G) and Apoptosis Inducing Factor (AIF) are two mitochondrial mediators that, upon their translocation to the nucleus, have the capability of producing large scale DNA fragmentation independently of caspases [16].

The important role of TNF- $\alpha$ in the apoptotic pathway is also supported by studies showing that anti-TNF antibodies are able to influence protein turnover and levels of ubiquitinproteasome components [76]. The ubiquitin-proteasome pathway represents the main pathway towards proteins degradation in muscle atrophy. This mechanism involves the targeted degradation of proteins via modification by ubiquitin and subsequent proteolysis by the $26 \mathrm{~S}$ proteasome [77]. In addition, a parallel and ubiquitin-independent mechanism of degradation for oxidatively modified proteins has been indicated in the $20 \mathrm{~S}$ core proteasome [78].

\section{PHYSICAL EXERCISE TO COUNTERACT THE SKELETAL MUSCLE LOSS}

If sarcopenia is indeed an important risk factor for clinical outcomes (especially physical disability) in older persons, interventions aimed at preventing/delaying/reducing its onset and/or progression are needed $[6,79]$. To date, the most promising data in this context are reported from clinical trials on physical exercise, especially resistance training. In fact, significant improvements in muscle strength and physical performance have been observed after physical exercise, even among very frail older persons. For example, it has been shown that a 10 -week resistance training program was able to significantly improve muscle strength by more than $125 \%$ (compared to less than a $3 \%$ change in the control group) in very old nursing home residents [80]. Through this improvement in muscle strength, participants also benefici- 
ated of significant and positive effects on gait speed, muscle power, and spontaneous physical activity. Moreover, it has been hypothesized that the frailest older persons are those who might better respond to the exercise intervention and report the larger improvements in their function, possibly because presenting larger margins of gain [81]. Interestingly, evidence in master atheletes confirms that the maintenance of an active lifestyle is associated with a lower muscle loss rate occurring with aging [82]. The improvements of muscle strength following a physical exercise intervention are directly associated with the increase of muscle quality. In fact, resistance training is able to increase the muscle fiber size (both type I and II) [83], the capillary density [84], and the number of myonuclei per fiber and myonuclei per unit length of muscle fiber [85]. Moreover, an increase of muscle protein synthesis (in particular of myosin heavy chains) has been observed with physical activity [86-89].

It is noteworthy that the beneficial effects of physical activity and physical exercise may also be provided through indirect mechanisms. In fact, both in vitro and in vivo studies have demonstrated that physical exercise positively influence the systemic inflammatory status [90]. Moreover, physical exercise promotes changes in muscle innervation and activation patterns [91], and reduces the need of dietary protein intake (by improving the efficiency of protein absorption) $[92,93]$. It is also important to acknowledge that physical exercise has shown to be beneficial for a wide spectrum of clinical and subclinical conditions potentially responsible for acceleration of the age-related muscle loss [94-96].

\section{CONCLUSIONS}

The design of clinical trials on sarcopenia is urgent, given 1) the extremely paucity of current evidence, and 2) the importance of this age-related condition (as a marker of aging as well as a predictor of physical disability in the elderly). Unfortunately, several conceptual and methodological issues are still needed to be carefully and adequately addressed. In particular, further studies are needed to 1) clarify the clinical importance of sarcopenia beyond its role of aging marker, and 2) identify a critical, objective and standardized threshold of muscle decline associated with onset of healthrelated events. Studies should indeed verify whether sarcopenia might represent a marker of real clinical interest. Nevertheless, the skeletal muscle decline occurring with age is still one of the most peculiar features of the aging process.

If the detrimental effects of sarcopenia on the health status will be confirmed, future specifically designed studies should carefully explore the possible preventive interventions reducing the clinical and biological consequences of this age-related phenomenon. To date, among the possible strategies, the adoption of a healthier lifestyle based on regular physical activity is, not only the most promising intervention in terms of beneficial effects, but also the easiest one to pontentially be implemented on a large-scale and in a costeffective fashion, especially in older persons.

\section{ACKNOWLEDGEMENTS}

This work was supported by the University of Florida Institute on Aging and the Claude D. Pepper Older Americans Independence Center (NIH grant 1P30AG028740). Dr. Cesari's work is also supported by the National Institutes of
Health - National Institute on Aging (NIA grant 1R01AG026 556-01A2).

\section{REFERENCES}

[1] Baumgartner RN, Koehler KM, Gallagher D, et al. Epidemiology of sarcopenia among the elderly in New Mexico. Am J Epidemiol 1998; 147: 755-63.

[2] Morley JE, Baumgartner RN, Roubenoff R, Mayer J, Nair KS Sarcopenia. J Lab Clin Med 2001; 137: 231-43.

[3] Hughes VA, Frontera WR, Roubenoff R, Evans WJ, Fiatarone Singh MA. Longitudinal changes in body composition in older men and women: role of body weight change and physical activity. Am J Clin Nutr 2002; 76: 473-81.

[4] Herndon LA, Schmeissner PJ, Dudaronek JM, et al. Stochastic and genetic factors influence tissue-specific decline in ageing C. elegans. Nature 2002; 419: 808-14.

[5] Cesari M, Pahor M. Target population for clinical trials on sarcopenia. J Nutr Health Aging 2008; in press.

[6] Cesari M, Colloca G, Zamboni V, Pahor M. Sarcopenia and frailty in older women. In: Benninghouse BT, Rosset AG, editors. Women and aging: new research. First ed. Hauppage, NY: Nova Science Publisher, Inc; 2008. p. in press.

[7] Fried LP, Tangen CM, Walston J, et al. Frailty in older adults: evidence for a phenotype. J Gerontol A Biol Sci Med Sci 2001; 56: M146-M156.

[8] Cesari M, Leeuwenburgh C, Lauretani F, et al. Frailty syndrome and skeletal muscle - Results from the InCHIANTI study. Am J Clin Nutr 2006; 83: 1142-8.

[9] Janssen I. Influence of sarcopenia on the development of physical disability: the Cardiovascular Health Study. J Am Geriatr Soc 2006; 54: 56-62.

[10] Krakauer JC, Franklin B, Kleerekoper M, Karlsson M, Levine JA. Body composition profiles derived from dual-energy X-ray absorptiometry, total body scan, and mortality. Prev Cardiol 2004; 7: 10915.

[11] Janssen I, Shepard D, Katzmarzyk P, Roubenoff R. The health care costs of sarcopenia in the United States. J Am Geriatr Soc 2004; 52: $80-5$

[12] Delmonico MJ, Harris TB, Lee JS, et al. Alternative definitions of sarcopenia, lower extremity performance, and functional impairment with aging in older men and women. J Am Geriatr Soc 2007; 55: 769-74.

[13] Newman AB, Kupelian V, Visser M, et al. Strength, but not muscle mass, is associated with mortality in the Health, Aging and Body Composition Study cohort. J Gerontol A Biol Sci Med Sci 2006; 61A: 72-7.

[14] Lebrun CE, van der Schouw YT, de Jong FH, Grobbee DE, Lamberts SW. Fat mass rather than muscle strength is the major determinant of physical function and disability in postmenopausal women younger than 75 years of age. Menopause 2006; 13: 47481.

[15] Bortz WM, II. Disuse and aging. JAMA 1982; 248: 1203-8.

[16] Marzetti E, Leeuwenburgh C. Skeletal muscle apoptosis, sarcopenia and frailty at old age. Exp Gerontol 2006;41:1234-8.

[17] Roubenoff R, Hughes VA. Sarcopenia: current concepts. J Gerontol A Biol Sci Med Sci 2000; 55A: M716-M724.

[18] Burkinshaw L, Hill GL, Morgan DB. Assessment of the distribution of protein in the human body by in vivo neutron activation analysis. International Symposium on Nuclear Activation Techniques in the Life Sciences.Vienna, Austria: International Atomic Energy Association; 1978. p. 787-98.

[19] Cohn SH, Vartsky D, Yasumura S, et al. Compartmental body composition based on total-body nitrogen, potassium, and calcium. Am J Physiol 1980; 239: E524-E530.

[20] Wang ZM, Visser M, Ma R, et al. Skeletal muscle mass: evaluation of neutron activation and dual-energy X-ray absorptiometry methods. J Appl Physiol 1996; 80: 824-31.

[21] Proctor DN, O'Brien PC, Atkinson EJ, Nair KS. Comparison of techniques to estimate total body skeletal muscle mass in people of different age groups. Am J Physiol Endocrinol Metab 1999; 277: E489-E495.

[22] Fuller NJ, Hardingham CR, Graves M, et al. Predicting composition of leg sections with anthropometry and bioelectrical impedance analysis, using magnetic resonance imaging as reference. Clin Sci (Lond) 1999; 96: 647-57. 
[23] Rolland Y, Lauwers-Cances V, Cournot M, et al. Sarcopenia, calf circumference, and physical function of elderly women: a crosssectional study. J Am Geriatr Soc 2003; 5: 1120-4.

[24] Heymsfield SB, Olafson RP, Kutner MH, Nixon DW. A radiographic method of quantifying protein-calorie undernutrition. Am J Clin Nutr 1979; 32: 693-702.

[25] Heymsfield SB, McManus C, Smith J, Stevens V, Nixon DW. Anthropometric measurement of muscle mass: revised equations for calculating bone-free arm muscle area. Am J Clin Nutr 1982; 36: 680-90.

[26] Marcell TJ. Sarcopenia: causes, consequences, and preventions. J Gerontol A Biol Sci Med Sci 2003; 58A(10): 911-6.

[27] Janssen I, Heymsfield SB, Ross R. Low relative skeletal muscle mass (sarcopenia) in older persons is associated with functional impairment and physical disability. J Am Geriatr Soc 2002; 50: 889-96.

[28] World Health Organization. Nutritional anemias: Report of a WHO Scientific Group. Geneva: World Health Organization; 1968.

[29] Janssen I, Baumgartner RN, Ross R, Rosenberg IH, Roubenoff R. Skeletal muscle cutpoints associated with elevated physical disability risk in older men and women. Am J Epidemiol 2004; 159: 41321.

[30] Frontera WR, Suh D, Krivickas LS, Hughes VA, Goldstein R, Roubenoff R. Skeletal muscle fiber quality in older men and women. Am J Physiol Cell Physiol 2000; 279: 611-8.

[31] Visser M, Kritchevsky SB, Goodpaster BH, et al. Leg muscle mass and composition in relation to lower extremity performance in men and women aged 70 to 79: the Health, Aging, and Body Composition study. J Am Geriatr Soc 2002; 50: 897-904.

[32] Visser M, Goodpaster BH, Kritchevsky SB, et al. Muscle mass, muscle strength, and muscle fat infiltration as predictors of incident mobility limitations in well-functioning older persons. J Gerontol A Biol Sci Med Sci 2005; 60A: 324-33.

[33] Reed RL, Pearlmutter L, Yochum K, Meredith KE, Mooradian AD. The relationship between muscle mass and muscle strength in the elderly. J Am Geriatr Soc 1991; 39: 555-61.

[34] Metter EJ, Lynch N, Conwit R, Lindle R, Tobin J, Hurley B. Muscle quality and age: cross-sectional and longitudinal comparisons. J Gerontol 1999; 54A: B207-B218.

[35] Lauretani F, Russo CR, Bandinelli S, et al. Age-associated changes in skeletal muscles and their effect on mobility: an operational diagnosis of sarcopenia. J Appl Physiol 2003; 95: 1851-60.

[36] Forbes GB. Longitudinal changes in adult fat-free mass: influence of body weight. Am J Clin Nutr 1999;70:1025-31.

[37] Newman AB, Kupelian V, Visser M, et al. Sarcopenia: alternative definitions and associations with lower extremity function. J Am Geriatr Soc 2003; 51: 1602-9.

[38] Tanko LB, Movsesyan L, Svendsen OL, Christiansen C. The effects of hormone replacement therapy on appendicular lean tissue mass in early postmenopausal women. Menopause 2002; 9(2): 11721.

[39] Melton LJ, III, Khosla S, Riggs BL. Epidemiology of sarcopenia. Mayo Clin Proc 2000; 75(Suppl): S10-S13.

[40] Goodpaster BH, Kelley DE, Thaete FL, He J, Ross R. Skeletal muscle attenuation determined by computed tomography is associated with skeletal muscle lipid content. J Appl Physiol 2000; 89: 104-10.

[41] Roubenoff R, Harris TB, Abad LW, Wilson PWF, Dallal GE, Dinarello CA. Monocyte cytokine production in an elderly population: effect of age and inflammation. J Gerontol 1998; 53A: M20M26.

[42] Bales CW, Ritchie CS. Sarcopenia, weight loss, and nutritional frailty in the elderly. Annu Rev Nutr 2002; 22: 309-23.

[43] Anker SD, Ponikowski PP, Clark AL, et al. Cytokines and neurohormones relating to body composition alterations in the wasting syndrome of chronic heart failure. Eur Heart J 1999; 20: 683-93.

[44] Garcia-Martinez C, Lopez-Soriano FJ, Argiles JM. Acute treatment with tumor necrosis factor-alpha induces changes in protein metabolism in rat skeletal muscle. Mol Cell Biochem 1993; 125: 11-8.

[45] Hoshino E, Pichard C, Greenwood CE, et al. Body composition and metabolic rate in rat during a continuous infusion of cachectin. Am J Physiol 1991; 260: E27-E36.

[46] Charters Y, Grimble RF. Effects of recombinant human tumor necrosis factor alpha on protein synthesis in liver, skeletal muscle and skin of rats. Biochem J 1989; 258: 493-7.
[47] Phillips T, Leeuwenburgh C. Muscle fiber-specific apoptosis and TNF-alpha signaling in sarcopenia are attenuated by life-long calorie restriction. FASEB J 2005; 19: 668-70.

[48] Greiwe JS, Cheng B, Rubin DC, Yarasheski KE, Semenkovich CF. Resistance exercise decreases skeletal muscle tumor necrosis factor alpha in frail elderly humans. FASEB J 2001; 15: 984-95.

[49] Roubenoff R, Parise H, Payette HA, et al. Cytokines, insulin-like growth factor 1 , sarcopenia, and mortality in very old communitydwelling men and women: the Framingham Heart Study. Am J Med 2003; 115: 429-35.

[50] Chandalia M, Abate N. Metabolic complications of obesity: inflated or inflamed? J Diabetes Complicat 2007; 21: 128-36.

[51] Schaap LA, Pluijm SM, Deeg DJ, Visser M. Inflammatory markers and loss of muscle mass (sarcopenia) and strength. Am J Med 2006; 119: 526.e9-526.e17.

[52] Petersen AMW, Pedersen BK. The anti-inflammatory effect of exercise. J Appl Physiol 2005; 98: 1154-62.

[53] Roubenoff R. Catabolism of aging: is it an inflammatory process? Curr Opin Clin Nutr Metab Care 2003; 6: 295-9.

[54] Moreira AL, Sampaio EP, Zmuidzinas A, Frindt P, Smith KA, Kaplan G. Thalidomide exerts its inhibitory action on tumor necrosis factor alpha by enhancing mRNA degradation. J Exp Med 1993; 177: $1675-80$.

[55] Gordon JN, Trebble TM, Ellis RD, Duncan HD, Johns T, Goggin PM. Thalidomide in the treatment of cancer cachexia: a randomised placebo controlled trial. Gut 2005; 54: 540-5.

[56] Khan ZH, Simpson EJ, Cole AT, et al. Oesophageal cancer and cachexia: the effect of short-term treatment with thalidomide on weight loss and lean body mass. Aliment Pharmacol Ther 2003; 17 677-82.

[57] Emilie D, Wijdenes J, Gisselbrecht C, et al. Administration of an anti-interleukin-6 monoclonal antibody to patients with acquired immunodeficiency syndrome and lymphoma: effect on lymphoma growth and on B clinical symptoms. Blood 1994; 84: 2472-9.

[58] Moyland JS, Reid MB. Oxidative stress, chronic disease, and muscle wasting. Muscle Nerve 2007; 35: 411-29.

[59] Il'yasova D, Ivanova A, Morrow JD, Cesari M, Pahor M. Correlation between two markers of inflammation, serum C-reactive protein and interleukin-6, and indices of oxidative stress in patients with high risk of cardiovascular disease. Biomarkers 2008; 13: 4151 .

[60] Tosato M, Zamboni V, Ferrini A, Cesari M. The aging process and potential interventions to extend life expectancy. Clin Interv Aging 2007; 2: 401-12.

[61] De La Fuente M. Effects of antioxidants on immune system ageing. Eur J Clin Nutr 2002; 56: S5-S8.

[62] Carmeli E, Coleman R, Reznick AZ. The biochemistry of aging muscle. Exp Gerontol 2002; 37: 477-89.

[63] Cesari M, Kritchevsky SB, Leeuwenburgh C, Pahor M. Oxidative damage and platelet activation as new predictors of mobility disability and mortality in elders. Antioxid Redox Signal 2005; 8: 609-19.

[64] Howard C, Ferrucci L, Sun K, et al. Oxidative protein damage is associated with poor grip strength among older women living in the community. J Appl Physiol 2007; 103: 17-20.

[65] Semba RD, Ferrucci L, Sun K, et al. Oxidative stress is associated with greater mortality in older women living in the community. $\mathrm{J}$ Am Geriatr Soc 2007; 55: 1421-5.

[66] Cesari M, Kritchevsky SB, Nicklas BJ, et al. Lipoprotein peroxidation and mobility limitation - Results from the Health, Aging and Body Composition Study. Arch Intern Med 2005; 165: 2148-54.

[67] Semba RD, Ferrucci L, Sun K, et al. Oxidative stress and severe walking disability among older women. Am J Med 2007; 120 1084-9.

[68] Ji LL, Gomez-Cabrera MC, Vina J. Role of nuclear factor kappaB and mitogen-activated protein kinase signaling in exercise-induced antioxidant enzyme adaptation. Appl Physiol Nutr Metab 2007; 32: 930-5.

[69] Kramer HF, Goodyear LJ. Exercise, MAPK, and NF-kappaB signaling in skeletal muscle. J Appl Physiol 2007; 103: 388-95.

[70] Glass DJ. Skeletal muscle hypertrophy and atrophy signaling pathways. Int J Biochem Cell Biol 2005; 37: 1974-84.

[71] Semba RD, Blaum C, Guralnik JM, Moncrief DT, Ricks Mo, Fried LP. Carotenoid and vitamin E status are associated with indicators of sarcopenia among older women living in the community. Aging Clin Exp Res 2003; 15: 482-7. 
[72] Semba RD, Lauretani F, Ferrucci L. Carotenoids as protection against sarcopenia in older adults. Arch Biochem Biophys 2007; 458: 141-5.

[73] Cesari M, Pahor M, Bartali B, et al. Antioxidants and physical performance in elderly persons: the Invecchiare in Chianti (InCHIANTI) study. Am J Clin Nutr 2004; 79: 289-94.

[74] Sacheck JM, Milbury PE, Cannon JG, Roubenoff R, Blumberg JB. Effect of vitamin $\mathrm{E}$ and eccentric exercise on selected biomarkers of oxidative stress in young and elderly men. Free Radic Biol Med 2003; 34: 1575-88.

[75] Beg AA, Baltimore D. An essential role for NF-kappaB in preventing TNF-alpha-induced cell death. Science 1996; 274: 782-4

[76] Costelli P, Carbo' N, Tessitore L, et al. Tumor necrosis factor-alpha mediates changes in tissue protein turnover in rat cancer cachexia model. J Clin Invest 1993; 92: 2783-9.

[77] Robinson PA, Ardley HC. Ubiquitin-protein ligases. J Cell Sci 2004; 117: 5191-4.

[78] Grune T, Merker K, Sandig G, Davies KJ. Selective degradation of oxidatively modified protein substrates by the proteasome. Biochem Biophys Res Comm 2003; 305: 709-18.

[79] Bréchat PH, Lonsdorfer J, Vogel T. [Health promotion, by safe, individualized, and accessible physical activities and sports]. Presse Med 2007; 36(3 Pt 1): 379-80.

[80] Fiatarone MA, O'Neill EF, Ryan ND, et al. Exercise training and nutritional supplementation for physical frailty in very elderly people. N Engl J Med 1994; 330: 1769-75.

[81] Bortz WM, II. A conceptual framework of frailty: a review. J Gerontol A Biol Sci Med Sci 2002; 57A: M283-M288.

[82] Hawkins SA, Wiswell RA, Marcell TJ. Exercise and the master athletes - A model of successful aging? J Gerontol A Biol Sci Med Sci 2003; 58: 1009-11.

[83] Larsson L. Physical training effects on muscle morphology in sedentary males at different ages. Med Sci Sports Exerc 1982; 14: $203-$ 6.

[84] Hagerman FC, Walsh SJ, Staron RS, et al. Effects of high-intensity resistance training on untrained older men. I - Strength, cardiovascular, and metabolic responses. J Gerontol A Biol Sci Med Sci 2000; 55: B336-B346.

[85] Hikida RS, Staron RS, Hagerman FC, et al. Effects of highintensity resistance training on untrained older men. II - Muscle fi- ber characteristics and nucleo-cytoplasmatic relationships. J Gerontol A Biol Sci Med Sci 2000; 55: B347-B354.

[86] Yarasheski KE, Pak-Loduca J, Hasten DL, Obert KA, Brown MB, Sinacore DR. Resistance exercise training increases mixed muscle protein synthesis rate in frail womena and men $>/=76 \mathrm{yr}$ old. Am J Physiol 1999; 277(1 Pt 1): E118-E125.

[87] Balagopal P, Schimke JC, Ades P, Nair KS. Age effect on transcript levels and synthesis rate of muscle $\mathrm{MHC}$ and response to resistance exercise. Am J Physiol Endocrinol Metab 2001; 280: E203-E208.

[88] Hasten DL, Pak-Loduca J, Obert KA, Yarasheski KE. Resistance exercise acutely increases MHC and mixed muscle protein synthesis rates in 78-84 and 23-32 yr olds. Am J Physiol Endocrinol Metab 2000; 278: E620-E626.

[89] Welle S, Thornton C, Statt M. Myofibrillar protein synthesis in young and old human subjects after three months of resistance training. Am J Physiol 1995; 268: E422-E427.

[90] Bruunsgaard H. Physical activity and modulation of systemic lowlevel inflammation. J Leukoc Biol 2005; in press.

[91] Rooks DS, Kiel DP, Parsons C, Hayes WC. Self-paced resistance training and walking exercise in community-dwelling older adults: effects on neuromotor performance. J Gerontol A Biol Sci Med Sci 1997; 52: M161-M168.

[92] Evans WJ. Protein, nutrition and aging. J Am Coll Nutr 2004; 23(Suppl 6): 601S-9S.

[93] Bermon S, Hebuterne X, Peroux JL, Marconnet P, Rampal P. Correction of protei-energy malnutrition in older adults: effects of a short-term aerobic training program. Clin Nutr 1997; 16: 291-8.

[94] Beere PA, Russell SD, Morey MC, Kitzman DW, Higginbotham MB. Aerobic exercise training can reserve age-related peripheral circulatory changes in healthy older men. Circulation 1999; 100: 1085-94.

[95] Ogawa T, Spina RJ, Martin WH, III, et al. Effects of aging, sex, and physical training on cardiovascular responses to exercise. Circulation 1992; 86: 494-503.

[96] Hagberg JM, Graves JE, Limacher M, et al. Cardiovascular responses of 70- to 79-yr-old men and women to exercise training. J Appl Physiol 1989; 66: 2589-94.

(c) Cesari et al.; Licensee Bentham Open.

This is an open access article distributed under the terms of the Creative Commons Attribution License (http://creativecommons.org/licenses/by/2.5/), which permits unrestrictive use, distribution, and reproduction in any medium, provided the original work is properly cited. 